\title{
Experimental analysis of SiC-based refractory concrete in hybrid rocket nozzles
}

\author{
Raffaele D'Elia ${ }^{\mathrm{a}, \mathrm{b}, *}$, Gérard Bernhart $^{\mathrm{a}}$, Jouke Hijlkema ${ }^{\mathrm{c}}$, Thierry Cutard ${ }^{\mathrm{a}}$
}

\author{
a Université de Toulouse, CNRS, Mines Albi, INSA, UPS, ISAE, ICA (Institut Clément Ader), Campus Jarlard, F-81013 Albi, France \\ ${ }^{\mathrm{b}}$ CNES - Direction des Lanceurs, 52 rue Jacques Hillairet, 75612 Cedex Paris, France \\ c ONERA, Centre Fauga-Mauzac, France
}

Keywords:

Hybrid rocket motor

Nozzle materials

Silicon carbide

Refractory concrete

Material ablation

Oxidation

\begin{abstract}
A B S T R A C T
Hybrid propulsion represents a good alternative to the more widely used liquid and solid systems. This technology combines some important specifications of the latters, as the possibility of re-ignition, thrust modulation, a higher specific impulse than solid systems, a greater simplicity and a lower cost than liquid systems. Nevertheless the highly oxidizing environment represents a major problem as regards the thermo-oxidation and ablative behavior of nozzle materials. The main goal of this research is to characterize a silicon carbide based micro-concrete with a maximum aggregates size of $800 \mu \mathrm{m}$, in a hybrid propulsion environment. The nozzle throat has to resist to a highly oxidizing polyethylene/nitrous oxide hybrid environment, under temperatures up to $2900 \mathrm{~K}$. Three tests were performed on concrete-based nozzles in HERA Hybrid Rocket Motor (HRM) test bench at ONERA. Pressure chamber evolution and observations before and after tests are used to investigate the ablated surface at nozzle throat. Ablation behavior and crack generation are discussed and some improvements are proposed.
\end{abstract}

\section{Introduction}

Although hybrid propulsion has been introduced since many years, it is only in the last two decades that in view of cheap and reliable access to space has attracted the interest of many researchers and some companies. The environment produced by this kind of propulsion is more oxidizing than that of solid and liquid rockets, inducing a more pronounced ablation of nozzle's throat. This represents an important challenge as regard performances and nozzle's operation time. Usually graphite nozzles are used for hybrid rocket motors, without posing particular attention to this aspect. Authors observed a significant lack of works conducted in this field. Ablation was more studied in the case of solid rocket motors [1-6]. One of the few works about erosion in hybrid rocket nozzles is that of Nasuti and Bianchi [7]. They conducted a numerical study on the erosion of graphite nozzles, coupling NavierStokes equations with thermo-chemical ablative model, taking into account heterogeneous chemical reactions at nozzle surface, chemical diffusion speed in the boundary layer, interaction between ablation products and boundary layer and conduction in the material. In this frame, the French Space Agency (CNES) launched

* Corresponding author at: Université de Toulouse, CNRS, Mines Albi, INSA, UPS, ISAE, ICA (Institut Clément Ader), Campus Jarlard, F-81013 Albi, France.

E-mail address: raffaele.delia176@gmail.com (R. D'Elia). in 2005 the PERSEUS project, to develop new technologies applicable to the satellite launchers of the future. The project is mainly carried out by students in Master of Science and $\mathrm{PhD}$ courses. This work has started in 2009, in the context of the PERSEUS/PEGASE macro-project, leaded by AJSEP and engineers from Herakles Company. Its purpose is to design, develop and test a new nozzle, made of an SiC (Silicon Carbide) based micro-concrete. In 2011 a new SiC-based micro-concrete with a maximum aggregates size of $800 \mu \mathrm{m}$ has been introduced, to face the problem of an important porosity degree in the material with a $3 \mathrm{~mm}$ aggregates size concrete. The use of concrete in nozzles is original, as in literature authors didn't find any work about this specific application. If the literature review is extended to concretes exposed to very high temperature and/or heat flux, some works can be found. It is the case of the Molten Core Concrete Interaction (MCCI), where liquid radioactive corium, generated by the fusion at around $2700 \mathrm{~K}$ of the nucleus of a nuclear reactor, interacts with refractory concrete that surround it [8-11]. Another case concerns the interaction between concretes and hot outlet gases in flame trench [12]. In a previous paper, D'Elia et al. [13] studied the behavior of this concrete in standard atmosphere ( 0.84 bars of pressure), under concentrated solar flow up to $13.5 \mathrm{MW} / \mathrm{m}^{2}$, using a solar furnace. Surface erosion in these conditions is governed by silicon carbide active oxidation, with linear mass loss and a maximum erosion speed of around $5 \mu \mathrm{m} / \mathrm{s}$. The goal of the present work is to extend this study to a hybrid propulsion environment, 
using the ONERA's HERA motor test bench. This study is mandatory because the environment in HRM is expected to be different with respect to the solar furnace conditions, in terms of pressure, flow velocity, oxidizing partial pressure and chemical composition. Erosion, ablation and oxidation phenomena observed in [13] will be referred as Static Oxidation, in opposition to the Ablation phenomenon observed at nozzle throat, under an HRM environment.

\section{Experiments}

The hybrid rocket motor test bench used to perform fire tests on concrete based nozzles is named HERA (Fig. 1) and is located in Mauzac (FRANCE), at ONERA laboratory. It is composed of a polyethylene (PE) fuel cylinder, with a circular channel in the middle, held within an aluminum cylinder and mounted on a test bench table with steel supports. The channel within the PE fuel works as combustion chamber of the hybrid rocket motor. Nitrous oxide $\left(\mathrm{N}_{2} \mathrm{O}\right)$ is used as oxidizer. It is kept in liquid state in a 3.5 liters tank before use, under a $70-80$ bars pressure (Fig. 1 ). Oxidizer is injected inside a pre-combustion chamber, where it is atomized, with a valve, located back to the combustion chamber. Oxidizer passes then through the combustion chamber: combustion is started with a pyrotechnic igniter, and can be stopped simply cutting off the oxidizer mass flow inside the chamber. A 36 bars chamber pressure is obtained for a $16 \mathrm{~mm}$ diameter of the nozzle's throat cross-section. These values are measured with two pressure sensors, located at the beginning and at the end of the combustion chamber. The second one is less reliable, because of its position close to the nozzle entrance. This is the reason why only data from the first sensor are considered in this paper.

Nozzles used in this study are made of a Silicon carbide based concrete $\left(80.0 \mathrm{wt} \% \mathrm{SiC}, 14.0 \mathrm{wt} \% \mathrm{Al}_{2} \mathrm{O}_{3}, 5.0 \mathrm{wt} \% \mathrm{SiO}_{2}\right.$, and $1.4 \mathrm{wt} \%$ $\mathrm{CaO})$. They are designed using ONERA standard test geometry, with a contraction ratio $\left(A_{\mathrm{c}} / A_{\mathrm{t}}\right)$ of 10.5 and an expansion ratio $\left(A_{\mathrm{e}} /\right.$ $A_{\mathrm{t}}$ ) of 4.0. ONERA CAD files were used to design mold geometry on CATIA. A resin-based mold was chosen to cast the concrete. Concrete's processing route is based on the same process explained in a previous work [13]. Concrete is mixed with a $8.3 \mathrm{wt} \%$ water content during $6 \mathrm{~min}$. Then it is poured into the mold, located on a vibrating table, during $15-20 \mathrm{~min}$, to avoid macro-porosities generation. After that, material is maintained at $20^{\circ} \mathrm{C}$ under plastic films during $48 \mathrm{~h}$ to ensure correct hydration. Concrete nozzle is then unmolded and stabilized at $110^{\circ} \mathrm{C}$ during $24 \mathrm{~h}$, to ensure water evaporation and to avoid material spalling at high temperature. Nozzle's samples are finally fired at $1200{ }^{\circ} \mathrm{C}$ during $5 \mathrm{~h}$, to stabilize the microstructure, increase Young's modulus and reduce liquid phases generation during test at high temperature [1315]. Material's properties are summarized in Table 1. After

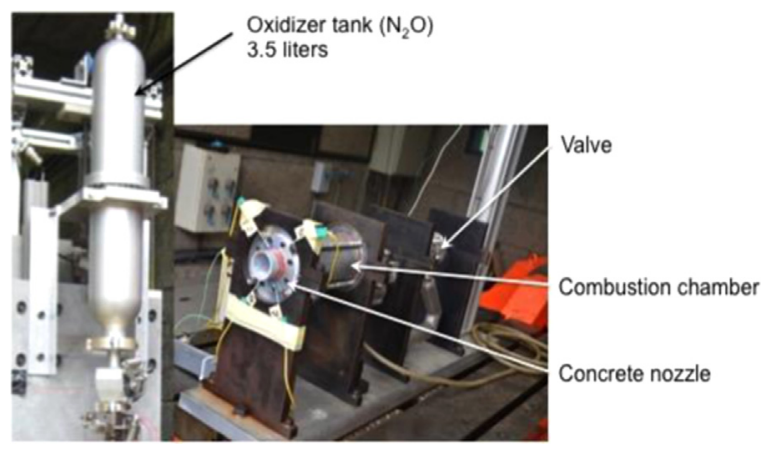

Fig. 1. HERA motor before a test. It is possible to notice the tank, the valve, the combustion chamber and the concrete nozzle. The igniter and the pre-chamber are not visible, because they are inside the engine.
Table 1

Physical and mechanical properties of the SiC-based micro-concrete [13]

\begin{tabular}{ll}
\hline Property & Micro-concrete \\
\hline Density $\left(\mathrm{kg} / \mathrm{m}^{3}\right)$ & 2580 \\
Coefficient of thermal expansion $\left(10^{-6} \mathrm{~K}^{-1}\right)$ & 5.75 \\
Young's modulus $\left(20-1200^{\circ} \mathrm{C}, \mathrm{GPa}\right)$ & 75.0 \\
Open porosity (vol\%) & 17.0 \\
\hline
\end{tabular}

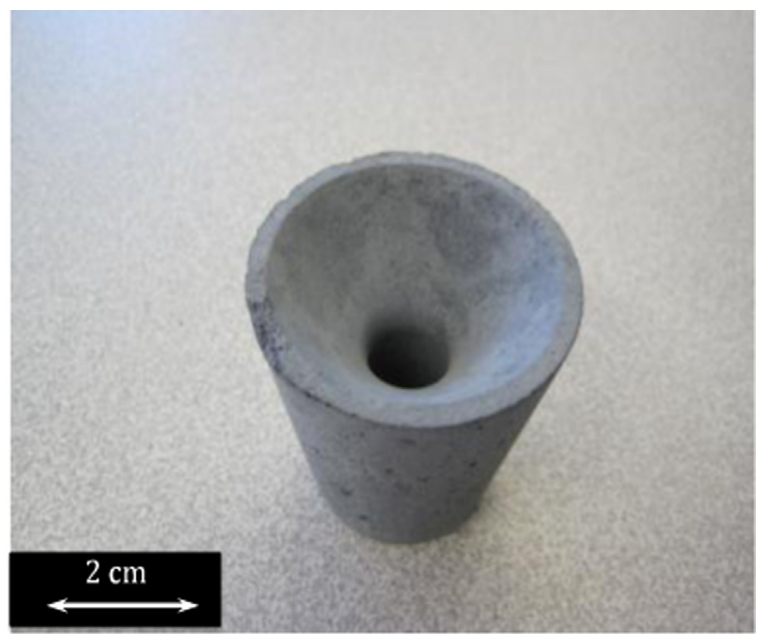

Fig. 2. SiC-based micro-concrete nozzle after manufacturing.

manufacturing (Fig. 2), nozzle is mounted at the end of the combustion chamber, directly in contact with the aluminum cylinder.

Three nozzles were tested in HERA motor, using ONERA geometry. The first two nozzles (HERA17 and 18) were only made with micro-concrete. The last one (HERA20) was made with micro-concrete, reinforced with $1 \mathrm{wt} \%$ of stainless steel short fibers $(0.55 \mathrm{~mm} \times 25 \mathrm{~mm})$ [16]. Processing route of the latter is slightly different from the classical method presented before. Fibers are first mixed with concrete during $5 \mathrm{~min}$, before the addition of water. After this step, material's processing route is the same as for the others two nozzles.

\section{Results}

First nozzle was tested during a fire test labeled HERA17, with a combustion time of $20 \mathrm{~s}$. The other two nozzles were tested during fire tests HERA18 and HERA20, with a combustion time of $10 \mathrm{~s}$. Pressure curves are presented in Fig. 3 for the three nozzle tests. During HERA17, chamber pressure (Fig. 3b) increases quickly from 0.1 (atmospheric pressure) to $0.36 \mathrm{MPa}$ in the first 0.7 test seconds. This phenomenon is generated by the transitory phase of ignition of the hybrid rocket motor. Then combustion starts and pressure increases from $0.36 \mathrm{MPa}$ to $0.51 \mathrm{MPa}$ after $9.2 \mathrm{~s}$. After a stationary phase of $1.7 \mathrm{~s}$, a pressure decrease is observed. This decrease continues until the end of combustion, after $20.2 \mathrm{~s}$, with a pressure of $0.32 \mathrm{MPa}$. A second transitory phase of $0.5 \mathrm{~s}$ is observed, due to the motor shutdown: pressure decreases down to $0.06 \mathrm{MPa}$ after $20.8 \mathrm{~s}$, with a de-pressurization with regard to the atmospheric pressure, to reach again an equilibrium state after $25 \mathrm{~s}$. This last phase of pressure equilibration is not considered in overall combustion time. Combustion of HERA17 motor can then be divided into 3 zones: ignition transitory, fuel regression and shutdown transitory. The end of ignition is defined as the moment when the injection pressure becomes constant (Fig. 3a). The end of combustion is the moment when the injection pressure falls very quickly, because no more oxidizer is injected in the combustion 


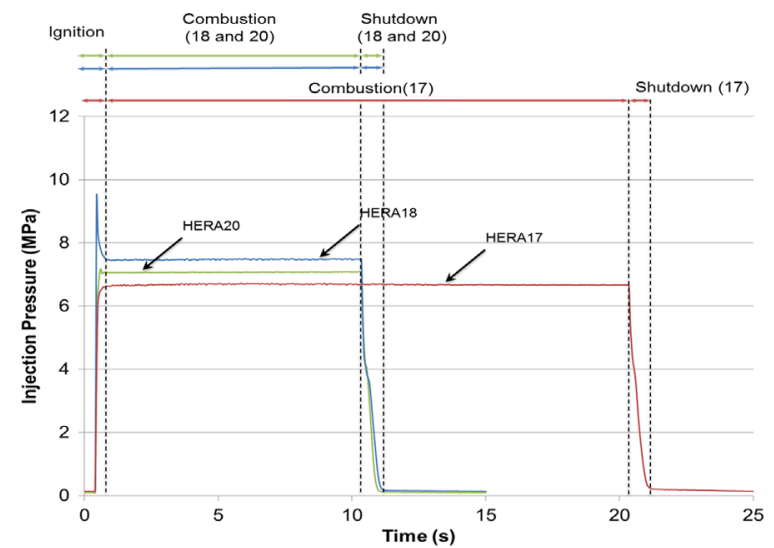

(a)

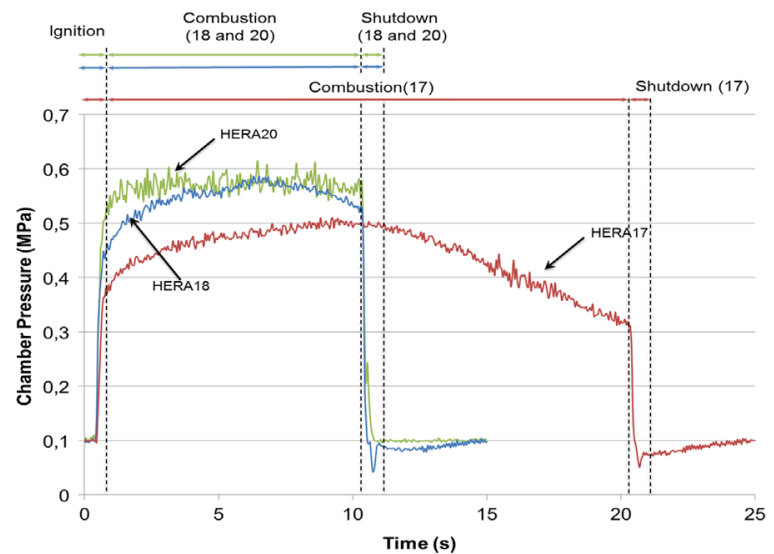

(b)

Fig. 3. Injection (a) and chamber (b) pressures evolution versus time, during nozzle tests HERA17, 18 and 20 (chamber pressure measured at the beginning of the combustion chamber)

chamber (Fig. 3a).

During fuel regression 3 sub-domains are observed: a. pressure increase, b. stationary pressure zone, c. pressure decrease. During this last phase, jet deviation and particles ejection are observed (Fig. 4a). Similar observations can be made for the test HERA18 and 20. In the last test HERA20, fuel regression seems to be almost completely stationary, after a little phase of pressure increase. According to the results of HERA17, these last two tests were performed with a combustion time of $10 \mathrm{~s}$, to avoid jet deviation and particle ejection (Fig. 4b), and for a better understanding of ablation phenomenon. Durations of different phases of combustion in the three tests performed are summarized in Table 2.

To correctly evaluate material behavior, some additional information is necessary, as the oxidizing species molar fraction and the static temperature at nozzle throat. Open source Rocket Propulsion Analysis (RPA) software ${ }^{a}$ is used to compute equilibrium calculation of the gas-dynamic flow in the nozzle. Combustion parameters are calculated introducing the following information into the software: chamber pressure, oxidizer and fuel chemical formula, mean mixing ratio, contraction and expansion ratio.

Chamber pressure used in the calculation is the value measured in the stationary pressure zone. Mixing ratio was calculated as follow:

\footnotetext{
${ }^{\mathrm{a}}$ http://propulsion-analysis.com/.
}

$O / F=\frac{\int_{t_{i}}^{t_{f}} \dot{m}_{0} d t}{M_{f}}$

where $O / F$ is the mean mixing ratio, $\dot{m}_{0}$ is the oxidizer mass flow $[\mathrm{kg} /$ s], measured at the inlet valve, $M_{f}$ is the fuel mass loss [kg], obtained from measurements before and after the test, $t_{i}$ and $t_{f}$ are the start time and the end time of combustion. Using these parameters, the information presented in Table 3 is obtained with RPA software. This program allows also the calculation of the gasdynamic field in a case of ideal combustion (stoichiometric mixing ratio, $\left.O / F_{\text {sto }}\right)$. The value obtained in this case is 7.46 , for a chamber pressure ranging from 0.4 to $0.6 \mathrm{MPa}$.

Images of nozzle's throat cross-section are taken before and after test, with a telecentric lens (TCZR072, OPTO Engineering), mounted on a 5 Megapixel Black/White camera (AVT Pike F505B, ALLIED Vision Technologies). This system allows a correct view of nozzle throat, avoiding chromatic aberration, normally generated using classical lens that introduces some errors in cross-section measurement during image post-treatment. In order to measure total ablated surface, images are treated with ImageJ open-source software. Ablated surface is calculated as the difference between the two surfaces, measured before $\left(S_{\text {initial }}\right)$ and after $\left(S_{\text {final }}\right)$ the test; an equivalent ablated radius $\left(r_{a b l}\right)$ is calculated as:

$r_{a b l}=r_{\text {final }}-r_{\text {initial }}=\sqrt{\frac{S_{\text {final }}}{\pi}}-\sqrt{\frac{S_{\text {initial }}}{\pi}}$

Cross-section evolutions for three different tests conditions are presented in Figs. 5b-d, in comparison with the untested nozzle (Fig. 5a). Ablated surface and equivalent ablated radius are presented in Table 4.

\section{Discussion}

\subsection{Separation of gas dynamic field}

Ablation was only observed for the first two nozzles tested at ONERA (HERA17 and 18). The last tested nozzle (HERA20) didn't show any erosion at nozzle throat. Separation of gas-dynamic flow could be a direct consequence of the ablation during the first test (HERA17), as observed in Fig. 4a. This test had a duration of $20 \mathrm{~s}$ and a jet flow deviation was observed after $10 \mathrm{~s}$. The asymmetric ablation of the nozzle throat, clearly observed in Fig. 5b, changes the gas dynamic field, introducing an instability, which leads to the separation. According to experimental observations [17,18], this phenomenon is normally generated in an over-expanded regime of the nozzle, when atmospheric pressure exceeds nozzle exit pressure by a factor of 2.5-4. Under these conditions, gas flow separation takes place, with recirculation zones in the divergent section and with instabilities. In this case, separation seems to be strictly related to nozzle's throat asymmetric ablation: when ablation is not observed at nozzle throat (HERA20), gas flow separation is not observed during the test. In the case of HERA18 nozzle, ablation was observed, but not jet deviation. It could be due to the fact that in this case the asymmetry of ablation at nozzle throat is not pronounced as in the case of HERA17. According to these observations it is possible to affirm that the separation phenomenon is a direct consequence of the asymmetric ablation of nozzle throat.

\subsection{Parameters influencing throat ablation rate}

Throat ablation rate is a strong function of mixture ratio and chamber pressure $[7,19,20]$.

A change of the mixture ratio of the test typically affects the 


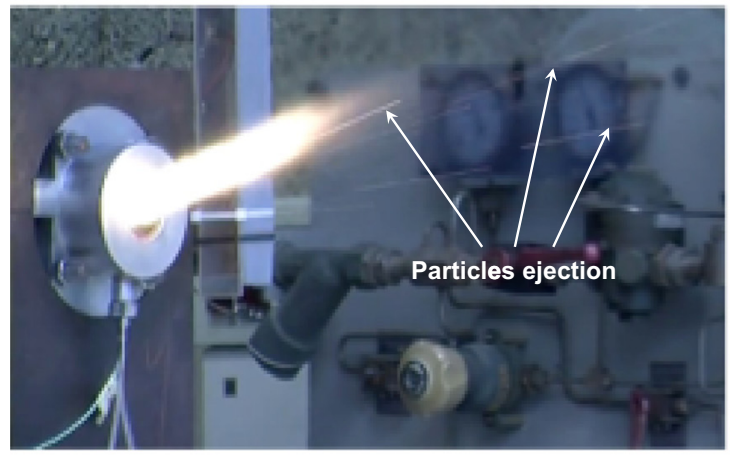

(a)

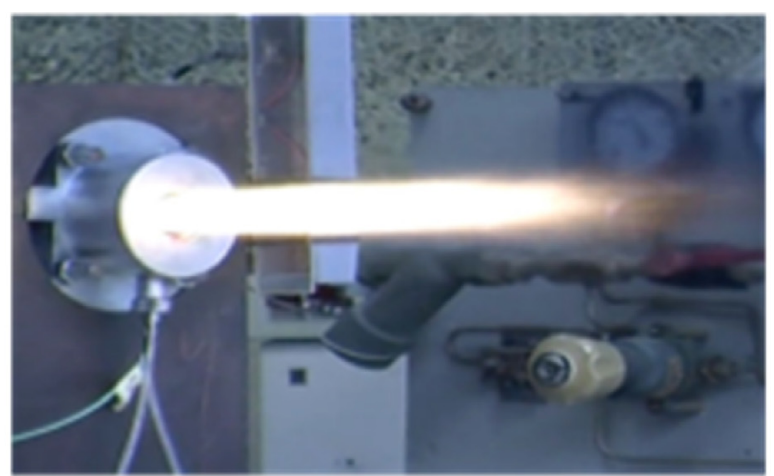

(b)

Fig. 4. (a) HERA17: jet deviation and particle ejection (white arrows) for a combustion time greater than $10 \mathrm{~s}$. (b) HERA18: for combustion time lower than $10 \mathrm{~s}$ neither jet deviation nor particle ejection are observed. The same behavior is observed for HERA20.

Table 2

Durations $(\Delta t)$ and pressure drop $(\Delta p)$ of the different combustion phases for the three tests performed at ONERA.

\begin{tabular}{|c|c|c|c|c|c|c|}
\hline & \multicolumn{2}{|l|}{ HERA17 } & \multicolumn{2}{|l|}{ HERA18 } & \multicolumn{2}{|l|}{ HERA20 } \\
\hline & $\Delta p(\mathrm{MPa})$ & $\Delta t(\mathrm{~s})$ & $\Delta p(\mathrm{MPa})$ & $\Delta t(\mathrm{~s})$ & $\Delta p(\mathrm{MPa})$ & $\Delta t(\mathrm{~s})$ \\
\hline Ignition transitory & +0.26 & 0.7 & +0.35 & 0.7 & +0.42 & 0.8 \\
\hline $\begin{array}{l}\text { Fuel regression ( } p \\
\text { increase) }\end{array}$ & +0.15 & 8.5 & +0.14 & 5.0 & +0.05 & 1.3 \\
\hline $\begin{array}{l}\text { Fuel regression (sta- } \\
\text { tionary } p \text { ) }\end{array}$ & - & 1.7 & - & 0.9 & - & 8.0 \\
\hline $\begin{array}{l}\text { Fuel regression ( } p \\
\text { decrease) }\end{array}$ & -0.20 & 9.3 & -0.06 & 3.4 & - & - \\
\hline Shutdown transitory & -0.26 & 0.5 & -0.49 & 0.9 & -0.48 & 0.5 \\
\hline $\begin{array}{l}\text { Overall combustion } \\
\text { time }\end{array}$ & & 20.7 & & 10.9 & & 10.6 \\
\hline
\end{tabular}

\section{Table 3}

Combustion parameters of the three tests performed at ONERA (* data are calculated with RPA software).

\begin{tabular}{|c|c|c|c|}
\hline & HERA17 & HERA18 & HERA20 \\
\hline$p_{c}(\mathrm{MPa})$ & 0.51 & 0.59 & 0.57 \\
\hline Average $\dot{m}_{o}(\mathrm{~g} / \mathrm{s})$ & 74.7 & 78.4 & 65.3 \\
\hline$M_{f}(\mathrm{~g})$ & 175 & 103 & 109 \\
\hline$O / F$ & 8.55 & 7.64 & 5.69 \\
\hline$p_{t}(\mathrm{MPa}) *$ & 0.29 & 0.32 & 0.32 \\
\hline$p_{\text {exit }}(\mathrm{MPa}) *$ & 0.03 & 0.03 & 0.02 \\
\hline$c^{*}(\mathrm{~m} / \mathrm{s})^{*}$ & 1536 & 1552 & 1543 \\
\hline$M_{\text {exit }}{ }^{*}$ & 2.51 & 2.53 & 2.67 \\
\hline$T_{t}(\mathbf{K}) *$ & 2897 & 2902 & 2673 \\
\hline $\mathrm{H}_{2} \mathrm{O}(\% \mathrm{~mol}){ }^{*}$ & 16.3 & 17.0 & 15.6 \\
\hline $\mathrm{CO}_{2}(\% \mathrm{~mol})^{*}$ & 10.3 & 9.3 & 5.0 \\
\hline $\mathrm{O}_{2}(\% \mathrm{~mol}) *$ & 2.0 & 0.9 & 0.0 \\
\hline
\end{tabular}

flame temperature (and the static temperature at nozzle throat) and the molar mass of oxidizing species at throat. This effect is clearly visible considering the difference between the second and the third test (HERA18 and 20), which have the same duration (10 s), but an important discrepancy in terms of average mixture ratio (7.64 vs. 5.69 ): this variation strongly affects the static temperature of the two tests (respectively $2900 \mathrm{~K}$ and $2673 \mathrm{~K}$ ) and molar mass of oxidizing species (respectively $17 \%$ mol and $15.6 \%$ mol for $\mathrm{H}_{2} \mathrm{O} ; 9.3 \%$ mol and $5 \%$ mol for $\mathrm{CO}_{2} ; 0.9 \% \mathrm{~mol}$ and $0.0 \%$ mol for $\mathrm{O}_{2}$ ). These values explain very well the strong difference observed in terms of ablated radius: the nozzle tested during the HERA18 test bench is subjected to an heavier thermo-chemical load, which activate earlier the ablation mechanisms.

The second parameter that has an influence on ablation speed is the chamber pressure. This is one of the most important parameters that can affect the throat erosion rate $[3,5,7,21,22]$. It is interesting to notice that in the case of HRMs the ablation rate increases linearly with chamber pressure [7], which is the same behavior already observed for solid rocket motors [3,5,21,22]. This effect can partially explain the difference observed in the first two tests performed (HERA17 and 18), where a difference of 0.8 bars is observed in terms of chamber pressure ( 5.1 bars and 5.9 bars respectively) during the stationary phase. However, this difference of pressure is too small to explain alone the reduction of $60 \%$ of the ablated radius, observed for the second test HERA18. In this first two tests, the mixture ratio are very close and so the molar mass of the oxidizing species and the static temperatures (Table 3 ). The only parameter that can explain the discrepancy of the ablated radius is the ablation time ( $20 \mathrm{~s}$ for HERA17 and $10 \mathrm{~s}$ for HERA18), which plays a fundamental part in the degradation of the nozzle throat and in the activation of the separation phenomenon, as described above.

\subsection{Chamber pressure vs. nozzle throat ablation}

In order to analyze the evolution of the pressure curves presented in Fig. 3b, it is useful to introduce the mass flow rate equation for an ideal compressible gas:

$\dot{m}_{t o t}=\frac{p_{c} A_{t}}{c^{*}} \rightarrow p_{c}=\frac{c^{*} \dot{m}_{t o t}}{A_{t}}$

where $p_{c}$ represents the chamber pressure $[\mathrm{Pa}], c^{*}$ is the characteristic exhaust velocity $[\mathrm{m} / \mathrm{s}], \dot{m}_{\text {tot }}=\dot{m}_{0}+\dot{m}_{f}$ is the overall mass flow $[\mathrm{kg} / \mathrm{s}]$ and $A_{t}$ is the nozzle throat cross-sectional surface $\left[\mathrm{m}^{2}\right]$. This equation shows that there are three main causes of the change in chamber pressure observed in Fig. 3b: mass flow rate $\left(\dot{m}_{\text {tot }}\right)$, characteristic exhaust velocity $\left(c^{*}\right)$ and the nozzle throat cross-sectional area $\left(A_{t}\right)$. In order to evaluate how these parameters changes with time and their impact on pressure curves, it is useful to analyze them according to HRM theory, as presented in Fig. 6. In this figure, $L$ is PE block/combustion chamber length [m], $D_{x}$ is the combustion chamber diameter $[\mathrm{m}], D_{t}$ is the nozzle throat diameter $[\mathrm{m}], \dot{r}$ is fuel regression rate $[\mathrm{m} / \mathrm{s}]$ and $\rho_{f}$ is fuel density $\left[\mathrm{kg} / \mathrm{m}^{3}\right]$.

The fuel surface regression rate, $\dot{r}$, where $r$ is the radius of the port, is usually determined by the oxidizer mass flux, generally following the expression developed by Marxman and Gilbert [23] and Marxman [24] in the early 1960s:

$\dot{r}=a_{0}\left(\frac{\dot{m}_{o}}{A_{x}}\right)^{n}=a_{0} G_{0}{ }^{n}$

where $a_{0}$ and $n$ are empirical constants, $\dot{m}_{0}$ is the oxidizer mass 


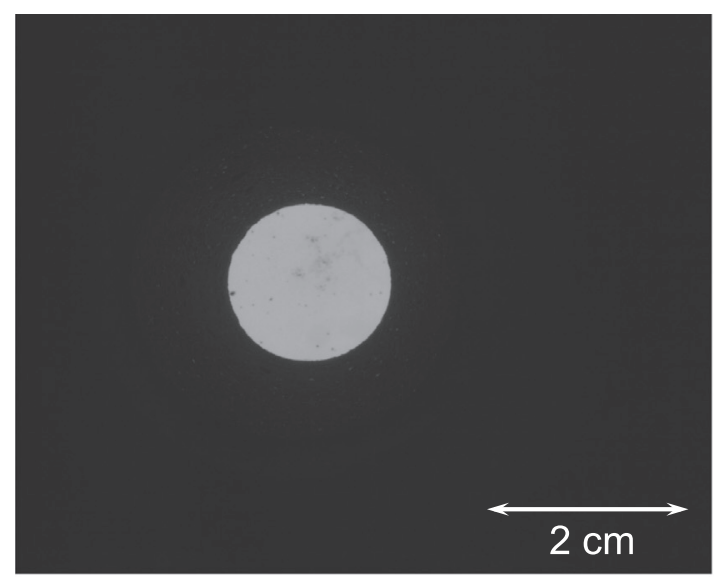

(a)

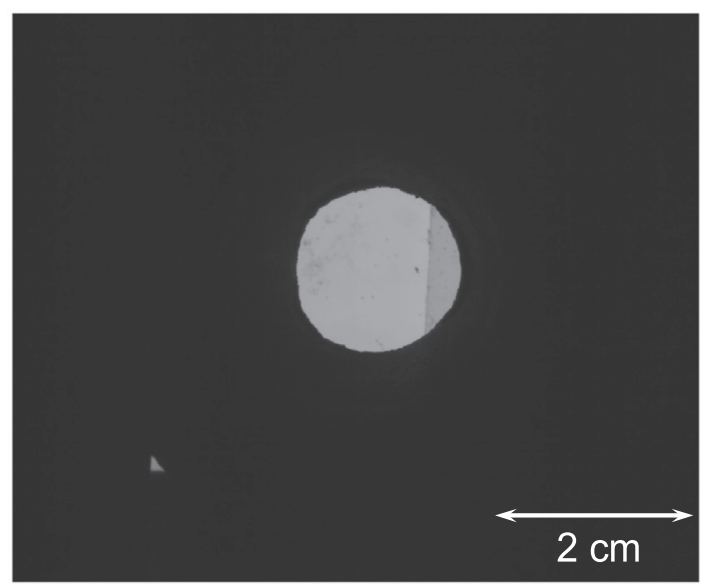

(c)

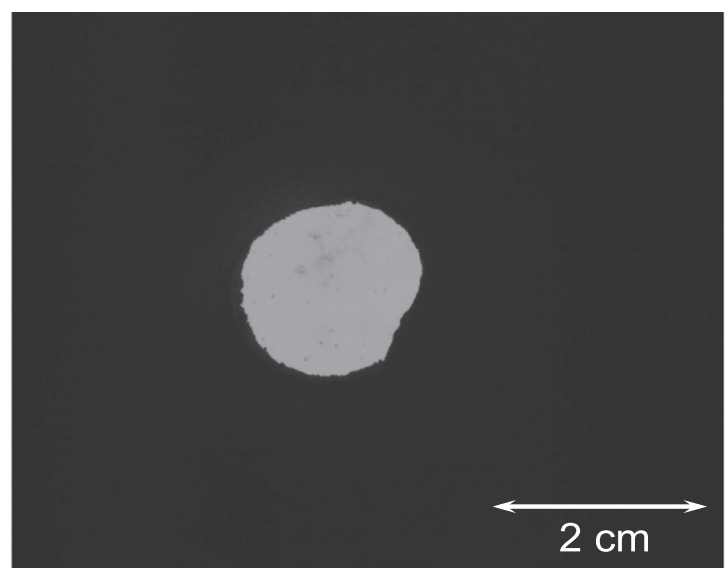

(b)

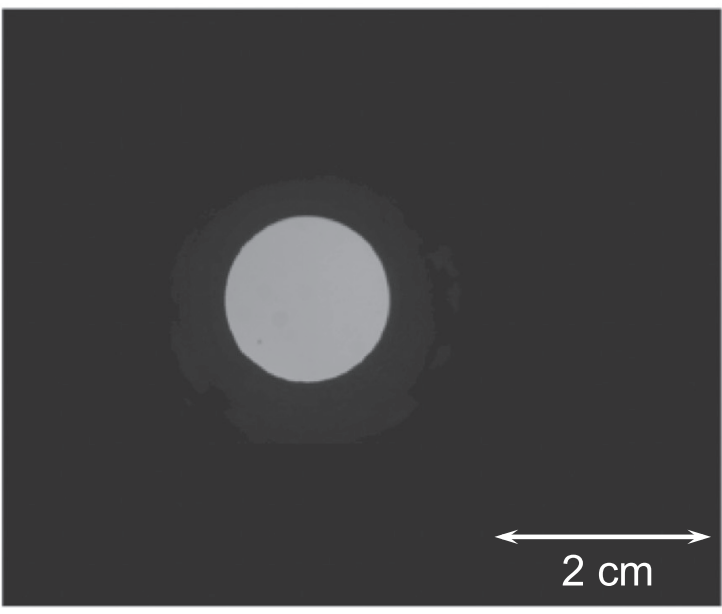

(d)

Fig. 5. Nozzle throat cross-sections before (a) and after (b-d) test. (a) Untested nozzle. (b) HERA17: 20 s. (c) HERA18: 10 s. (d) HERA20: 10 s.

Table 4

Ablated surfaces and equivalent ablated radius of HRM tests.

\begin{tabular}{lll}
\hline Test & Ablated surface $\left(\mathbf{m m}^{2}\right)$ & Equivalent ablated radius $(\mathbf{m m})$ \\
\hline HERA17 & 35.43 & 0.67 \\
HERA18 & 12.95 & 0.25 \\
HERA20 & 0.00 & 0.00 \\
\hline
\end{tabular}

flow $[\mathrm{kg} / \mathrm{s}], A_{x}=\pi D_{x}^{2}$ is the port cross-sectional area $\left[\mathrm{m}^{2}\right]$ and $G_{0}$ is the oxidizer mass flux $\left[\mathrm{kg} / \mathrm{m}^{2} \mathrm{~s}\right]$. The exponent $n$ is typically between 0.5 and 0.8 [25]. The fuel mass flow $\left(\dot{m}_{f},[\mathrm{~kg} / \mathrm{s}]\right)$ can be express as follow:

$\dot{m}_{f}=\dot{r} \cdot \rho_{f} \cdot \pi \cdot D_{X} \cdot L=K \cdot L \cdot \dot{m}_{o}{ }^{n} \cdot D_{X}{ }^{1-2 n}$

where $K=4^{n} \cdot a_{0} \cdot \rho_{f} \cdot \pi^{1-n}$. The characteristic exhaust velocity can be expressed as follow:

$c^{*}=\frac{\sqrt{R T_{C} / M}}{\Gamma}$

where $R$ is the gas constant $[8.3144 \mathrm{~J} / \mathrm{K} \mathrm{mol}], T_{C}$ is the combustion temperature of the mixture $[\mathrm{K}]$, which strongly depends upon the mixture ratio $O / F, M$ is the molar mass of the mixture $[\mathrm{g} / \mathrm{mol}]$ and $\Gamma$ is an adimensional parameter depending only on the adiabatic index $\gamma$ :
$\Gamma=\sqrt{\gamma}\left(\frac{2}{\gamma+1}\right)^{\frac{\gamma+1}{2(\gamma-1)}}$

Measurements, made on HERA motor test bench, have shown that oxidizer mass flow, after first ignition phase, does not change during test. According to this experimental observation and to Eqs. (3-7), and recalling that the exponent is generally in the range $0.5<n<0.8$, the following considerations can be pointed out:

1. As the port diameter $D_{x}$ increases with time and the oxidizer mass flow $\left(\dot{m}_{0}\right)$ is constant, the oxidizer mass flux $\left(G_{0}\right)$ decreases with time;

2. The first consequence of point 1 is the decrease with time of the fuel surface regression rate $\dot{r}$ (Eq. (4));

3. The second consequence of point 1 is the decrease of the fuel mass flow (Eq. (5)). Note that for an exponent $0.5<n<0.8$, the overall exponent of the port diameter $D_{x}$ is negative (1-2n);

4. The decrease of the fuel mass flow increases the mixing ratio $O /$ $F$ for a constant oxidizer mass flow, with a consequent evolution of the characteristic velocity $c^{*}$. This evolution depends upon the initial value of the $O / F$ ratio. Typically, the flame temperature shows a maximum for the stoichiometric condition $\left(O / F_{\text {sto }}\right)$ and tends to equally decrease for fuel- or oxidizer-rich mixtures [7]. The effect of this trend of the flame temperature is a maximum 

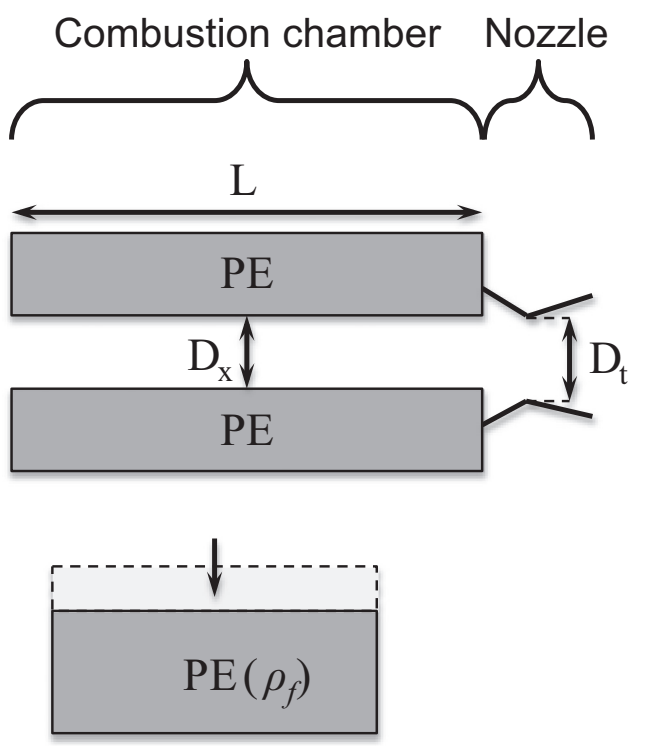

Fig. 6. HRM motor scheme.

for the characteristic velocity at the stoichiometric mixture ratio (Eq. (6));

5. The decrease of the fuel mass flow decreases the overall mass flow $\left(\dot{m}_{t o t}=\dot{m}_{f}+\dot{m}_{0}\right)$ for a constant oxidizer mass flow.

According to Eq. (3), if no ablation is observed (HERA20), the nozzle throat cross-sectional surface is constant during the test and there are only two components influencing the chamber pressure: the overall mass flow (which decreases with the combustion time) and the characteristic velocity. Since a constant pressure is observed during the HERA20 test, it is very likely that the characteristic velocity increases during the test, balancing the effect of the overall mass flow. This is possible if the $O / F$ initial value is below the optimal value: it is exactly the case of HERA20, where an average value of 5.67 is obtained (Table 3 ), clearly below the stoichiometric value of 7.46 .

When ablation is observed (HERA17 and 18), the nozzle throat cross-section $A_{t}$ is not constant anymore and its evolution will influence the chamber pressure value. $A_{t}$ can only increase with time, because of nozzle throat erosion, with a consequent decrease of chamber pressure. However, a decrease of chamber pressure can also be generated by the decrease of the characteristic velocity, if the mixing ratio $O / F$ exceeds the stoichiometric value during the test, and by the decrease of the overall mass flow, as discussed above. In Fig. 3b and in Tables 2, 3 sub-domains are observed during the fuel regression phase, characterized by three different evolutions of chamber pressure: a. pressure increase zone, b. stationary pressure zone and c. pressure decrease zone:

a. In the case of HERA17 and 18, the average mixing ratio (8.55 and 7.64 respectively) are above the stoichiometric value (7.46), but, since an increase in chamber pressure is observed in the initial phase of combustion, it is very likely that the $O / F$ in these phases are below the optimal value, generating an increase of $c^{*}$ and a consequent increase of pressure. It is not possible to affirm if in this phase nozzle ablation takes place, because the increase of pressure generated by the characteristic velocity could very well overwhelm both the effects of chamber pressure decrease generated by ablation (if it is already active) and by the overall mass flow $\left(\dot{m}_{\text {tot }}\right)$;

b. In the second phase of combustion a stationary zone is observed. During this phase the decrease in chamber pressure generated by $\dot{m}_{\text {tot }}$ and (possibly) by the ablation of nozzle throat is balanced by the characteristic velocity increase;

c. In the third phase a decrease in chamber pressure is observed. During this phase, the characteristic velocity has probably passed the stoichiometric value and it cannot balance anymore the others two effects generated by the ablation and by $\dot{m}_{\text {tot }}$, with a consequent decrease of the chamber pressure.

Ablation speed at nozzle throat is not constant, but depends on several parameters, as gas flow temperature and speed, oxidizing species molar fraction, surface roughness. It is not possible to correctly describe the evolution of all these parameters during the test. For this reason it is very difficult to understand when ablation starts exactly without any other data than the chamber pressure curves. However during the third sub-domain of the fuel regression phase of HERA17 test, a linear decrease of chamber pressure (clearly visible in Fig. 3b) suggests that nozzle ablation is already active: if the ablation phenomenon was activated during this phase, a further decrease in chamber pressure would change the slope of the curve. The separation of the gas dynamic field, observed for HERA17 after $10 \mathrm{~s}$ of tests, could be another element confirming the presence of material ablation in this phase. On the other hand, in the case of HERA18 the linear zone is very limited and the lack of separation does not help in the interpretation of results.

\subsection{Material surface analysis}

SEM images provide a better understanding of the material behavior at the microscopic level. Fig. 7 shows the nozzle after HERA17 test: the nozzle cross-section is presented on the left (a) and a SEM image of the nozzle throat is showed on the right (b). In the latter, nozzle throat can be divided in two zones: the first one (zone 1) on the top, where liquid phases are generated from micro-concrete at high temperature; the second one (zone 2 ), on the bottom of the image, shows a virgin surface, covered by some whiter particles.

A mixture of solidified liquid phases and silicon carbide aggregates composes the porous region on the top (zone 1). SiC aggregates at this temperature level $(2900 \mathrm{~K})$ undergo to active oxidation and sublimation. All these phenomena increase the erosion at material surface, with regard to static oxidation conditions in solar furnace [13]. However it is not possible to confirm active oxidation and sublimation of $\mathrm{SiC}$, because no direct observation of these phenomena was possible. Liquid phases, generated during the interaction between concrete surface and gas dynamic flow, can be seen as a moving front on the concrete, from the convergent to the divergent side, following the direction of the supersonic flow. Jet separation from the surface of the concrete may have occurred at the limit of this region (zone 1): this could explain why in zone 2, concrete does not seem to be attacked by the high reactive flow. Fig. 8 shows a detail of zone 1, observed on the top of Fig. 7b. In a previous work [13], surface of micro-concrete appears as completely different after exposition to a 13.5 MW/ $/ \mathrm{m}^{2}$ solar flow, with silicon-carbide aggregates that undergo active oxidation. A silicon carbide aggregate, during active oxidation (Fig. 9a and b), shows a classical oxidation crown, which is the consequence of $\mathrm{SiO}$ production at high temperature ( $>2100 \mathrm{~K}$ ). Gas static temperature at nozzle throat is $2900 \mathrm{~K}$, but oxidation crown neither silicon carbide aggregates can be directly observed. In contrary, the surface is covered by a solidified eutectic phase, generated at high temperature and solidified during nozzle cooling.

These phases have surrounded $\mathrm{SiC}$ aggregates that are not visible by SEM; the interaction with supersonic gas flow induces a movement towards the nozzle exit, with an increase of the nozzle throat cross-section. Therefore, it is not possible to confirm that 


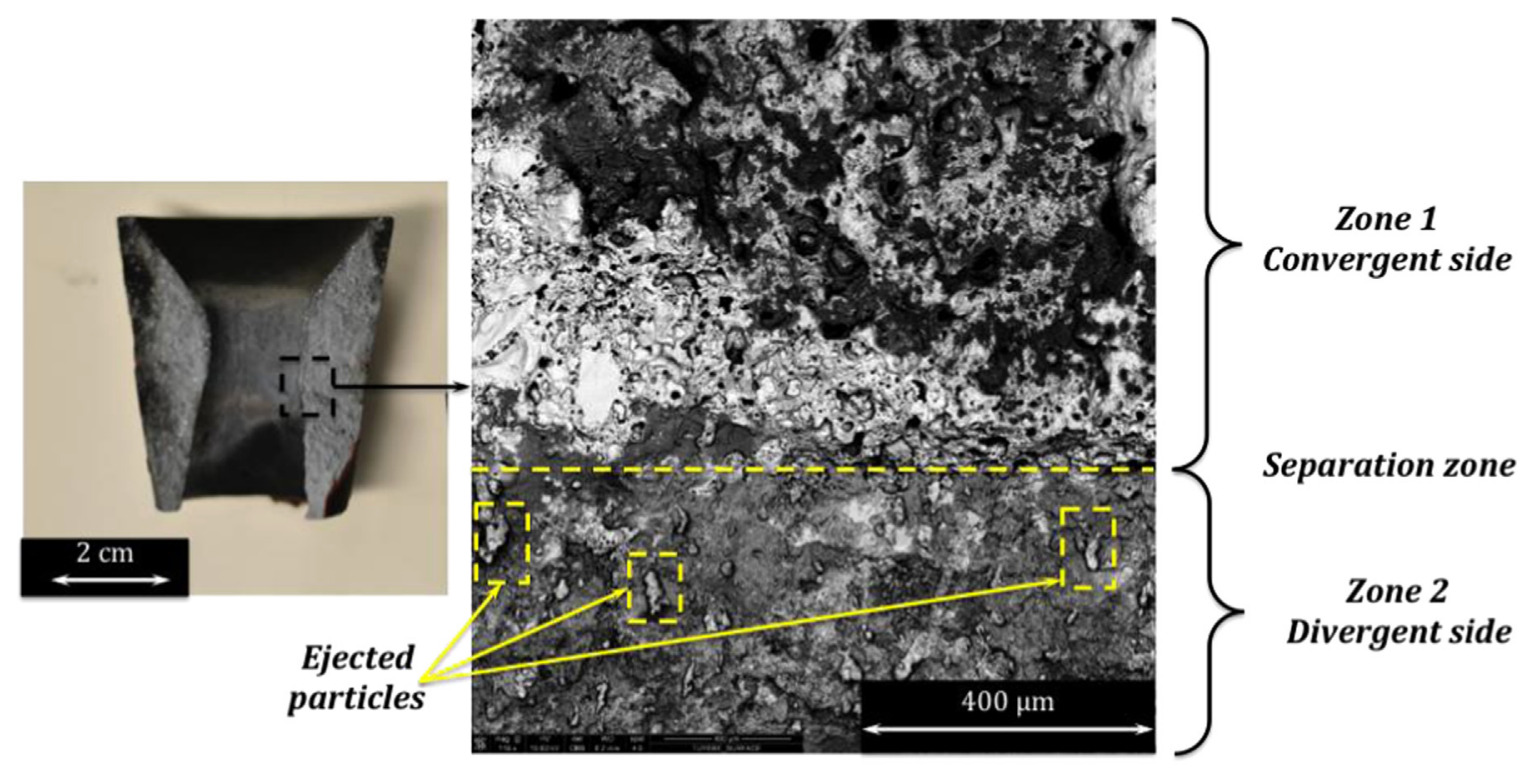

(a)

(b)

Fig. 7. HERA17 nozzle after test: (a) nozzle cross-section and (b) SEM image of the nozzle throat surface.

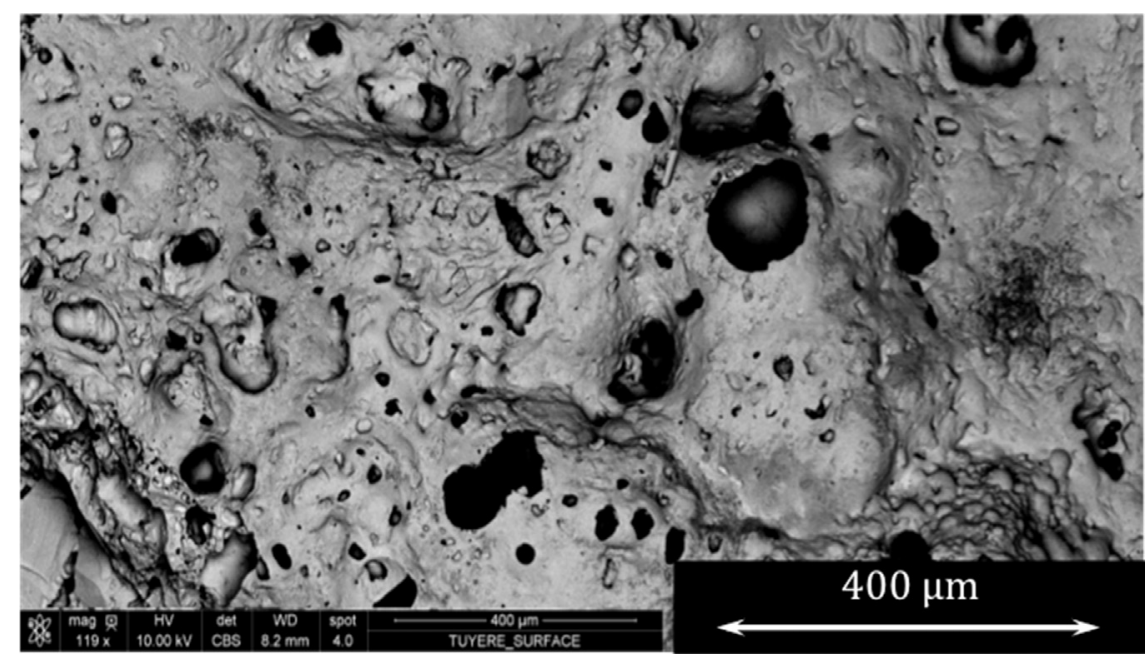

Fig. 8. HERA17 nozzle after test: SEM image of nozzle throat surface in the convergent side (zone 1).

silicon carbide active oxidation plays an active role in nozzle ablation. However when combustion time exceeds $10 \mathrm{~s}$, it is possible to observe particles ejected from the nozzle. These particles, which have redeposited on the virgin concrete surface (Fig. 7b), are probably generated by an intense active oxidation of silicon carbide at high temperature or by SiC sublimation. The dynamic ablation is therefore mainly generated by the interaction between the high temperature supersonic flow and the eutectic liquid phases, produced from the cementitious matrix at high temperature. The role of silicon carbide active oxidation/sublimation cannot be confirmed in this work.

It is interesting to notice that jet deviation, observed in Fig. 4a, is directed upwards; this observation might suggest a role of gravity in the liquid phases mobility at nozzle throat: the combined action of supersonic flow and gravity could generate liquid phases motion directed towards the exit of the nozzle and downwards, deviating the flow upwards. To validate this hypothesis it could be interesting to perform a firing test with the nozzle axis perpendicular to the ground (vertical test), since in this configuration the gas flow and the gravity would have the same direction, avoiding the asymmetry of the system.

After test, the first two nozzles (HERA17 and 18) showed two different types of crack: a longitudinal one (Fig. 10a, type 1) and a circumferential one (Fig. 10a and b, type 2). The third nozzle (HERA20) did not show any crack (Fig. 10c). The first two nozzles are composed of micro-concrete without any reinforcement. The last one contains $1 \mathrm{wt} \%$ of short metallic fibers. HERA17 test duration was of $20 \mathrm{~s}$ and jet deviation was observed, while HERA18 test duration was of $10 \mathrm{~s}$, without jet deviation. This difference appears to be critical in mechanical behavior of microconcrete, since a longitudinal crack appears when jet deviation is observed. The asymmetry of the gas dynamic field might suggest a tangential thermal gradient inside the structure, which could lead to this specific type of crack. HERA18 and 20 tests confirm the connection between jet deviation and the first kind of crack.

Otherwise, the second type of crack seems to be connected with the system configuration: the assembly/disassembly of the nozzle, its cooling phase or the geometry of the structure could 


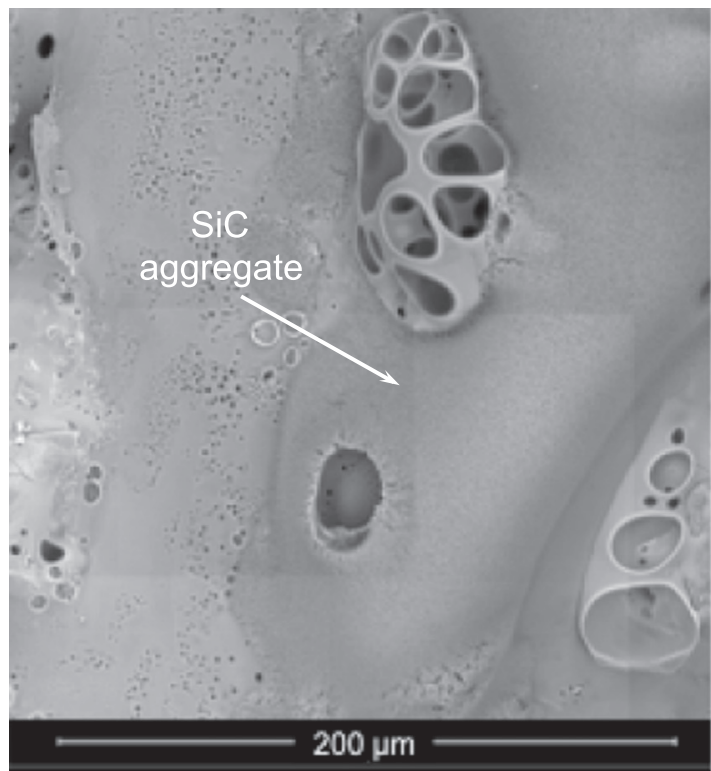

(a)

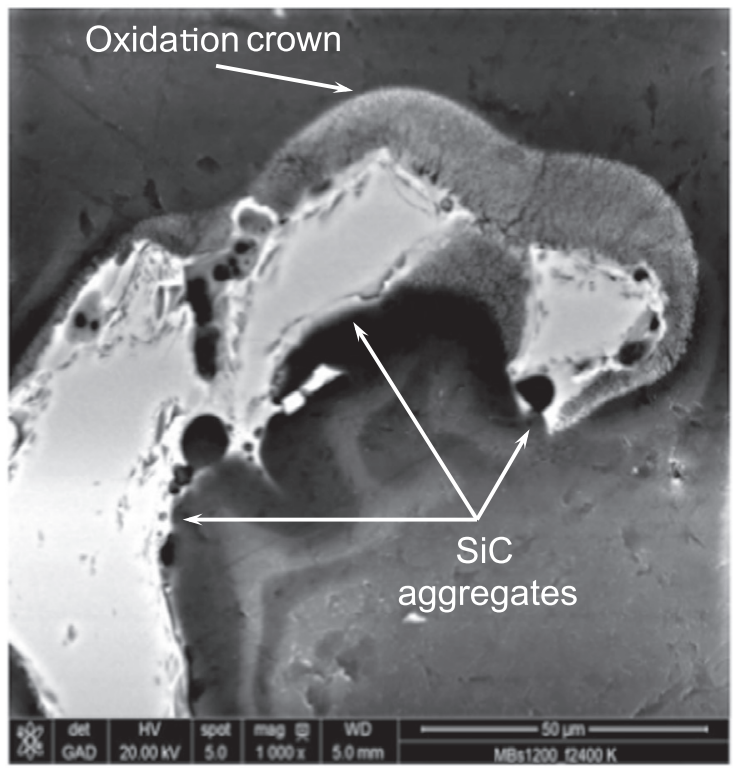

(b)

Fig. 9. Micro-concrete tested in a solar furnace [13], under a concentrated solar flux of $13.5 \mathrm{MW} / \mathrm{m}^{2}$ and a calculated surface temperature of $2400 \mathrm{~K}$ : (a) top view and (b) cross-section of $\mathrm{SiC}$ aggregates under active oxidation.

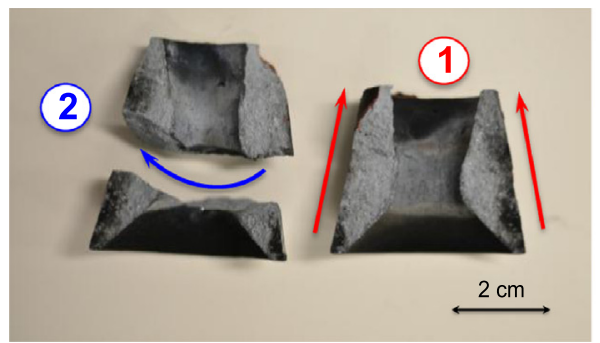

(a)

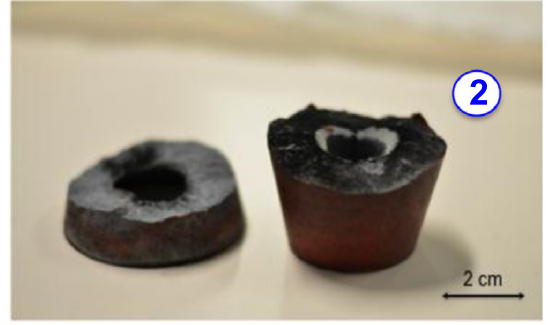

(b)

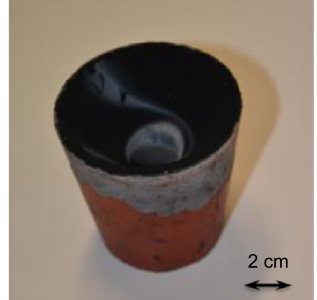

(c)

Fig. 10. HERA17 (a), HERA18 (b) and HERA20 (c) nozzles after test. Two types of cracks observed after HERA17 and HERA18 tests: longitudinal cracks (type 1) and circumferential crack (type 2).

induce some external stresses in the concrete, generating this kind of crack. The Fig. 10b might suggest that this crack was initiated during the combustion or during the assembly, because of the polyethylene black deposit on the crack surface. According to these observations it is possible to exclude that this second type of crack is initiated during the disassembly of the system or during material cooling, but it is not possible to confirm precisely if it is induced by the high thermal gradient or by stresses generated during the assembly phase. The two types of crack are the result of quasi-brittle rupture processes. Cementitious matrix boiling and/ or in-depth $\mathrm{SiC}$ aggregates oxidation/sublimation mechanisms at high temperature $(T>2100 \mathrm{~K})$ generate micro- and macro-porosities beneath the concrete surface. The result is a thin layer of porosities in depth in the material. The thickness of this layer increases with the diffusion of the oxidizing species, which depends on external conditions of temperature and pressure, but also on surface condition. The diffusion of these species in the material at high temperature contributes to material degradation and porosities generation. SEM images of the two breaking facets (vein profile side) are shown in Fig. 11. It is possible to notice two regions in both of the crack type ( 1 and 2 in Fig. 10a): a first zone of higher porosity, which reaches a depth close to $700 \mu \mathrm{m}$ for the longitudinal crack and close to $100 \mu \mathrm{m}$ for the circumferential crack. This strong difference likely depends on the surface condition of the zone where the crack is observed: the longitudinal crack (Fig. 11a) is observed beneath a very porous region of the concrete (zone 1 of Fig. 7b), where species diffusion is faster; the circumferential crack (Fig. 11b) is observed under a very compact region (zone 2 of Fig. 7b), where diffusion is more difficult.

This region represents the weakest zone in concrete, where it is most likely that fracture is initiated. Unfortunately these hypotheses need more studies to be confirmed. Therefore according to present results, it is not possible to confirm precisely the reasons of crack initiation and propagation. However the introduction of short metallic fibers in the third nozzle has shown the possibility to avoid crack initiation in this material, if combustion time is lower than $10 \mathrm{~s}$. This has been observed during the last test on concrete-based nozzle (HERA20), where no crack was observed after the test. Metallic fibers are randomly oriented inside the cementitious matrix because of vibration during concrete pouring into molds. As shown in previous works [16,26-28], the introduction of short metallic fibers in a refractory concrete allows to avoid its brittle behavior. On the one hand, diffuse damage develops in the reinforced refractory because of stress fields induced during the firing cycle, by a different dilatometric behavior between fibers and concrete constituents. Damage deals with micro- 


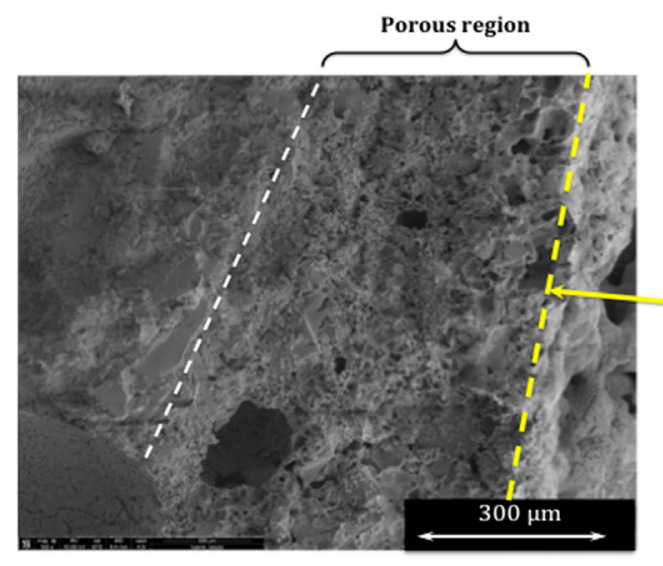

(a)

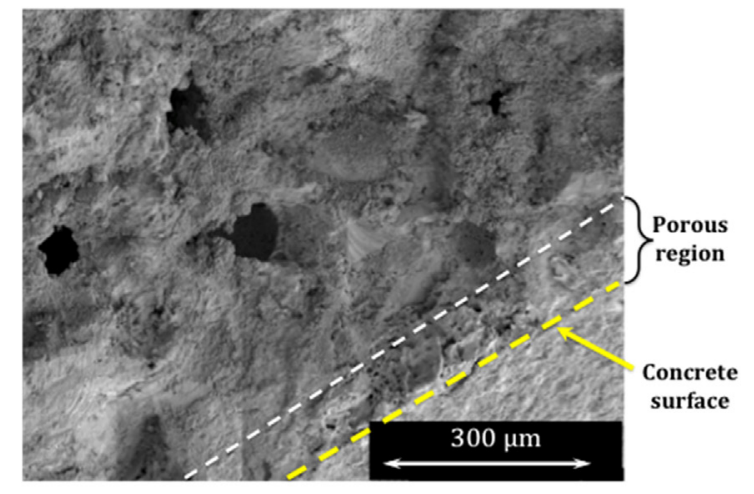

(b)

Fig. 11. HERA17 test: SEM images of longitudinal (a) and circumferential (b) breaking facets after test. It is possible to observe the concrete surface and the porous region. In figure (a) the surface of the concrete corresponds to the zone 1 observed in Fig. $7 \mathrm{~b}$; in figure (b) the surface corresponds to the zone 2 observed in Fig. $7 \mathrm{~b}$.

cracks in the cementitious matrix and with fiber/concrete debonding. On the other hand, fiber/concrete mechanisms take place in the material when mechanical loadings are applied either as an external loading or as loading due to thermal gradient. They deal with micro-crack and macro-crack bridging, with fiber/concrete debonding and interface phenomena and with fiber pull-out mechanisms. These various mechanisms make the refractory concrete more tolerant to damage and increase the non-linearity of its mechanical behavior. As a consequence, the reinforced concrete is able to develop a better resistance to deformation even if its stress capability is reduced.

\section{Conclusions}

Three SiC-based refractory micro-concrete nozzles have been tested in a hybrid rocket motor, under a highly oxidizing polyethylene/nitrous oxide environment. Nozzles were tested during $20 \mathrm{~s}$ (HERA17 test) and $10 \mathrm{~s}$ (HERA18 and 20 tests), under a static pressure at nozzle throat of around 3 bars and a static temperature at nozzle throat of $2700 \mathrm{~K}$ (HERA20 test) and $2900 \mathrm{~K}$ (HERA17 and 18 tests). Three combustion domains can be observed on pressure curves: ignition transitory, fuel regression and shutdown transitory. Image analysis of nozzle throat cross-section before and after test, gave an estimation of the ablated surface. This phenomenon was detected only in the first two nozzles (HERA17 and 18 tests), where the higher combustion temperatures and the more important concentration of the oxidizing species have probably played an important role in the activation of nozzle ablation. Separation of gas dynamic flow has been observed for a combustion time greater than $10 \mathrm{~s}$ in the case of HERA17. This phenomenon is strictly related to an asymmetric ablation at nozzle throat, generated by liquid phases interaction with supersonic gas dynamic flow. Gravity has probably an important role with regard to the asymmetric ablation, but a vertical test would be necessary to confirm it. No separation was observed in the case of HERA18, where the combustion time was probably too short to generate an asymmetric ablation of the nozzle throat. Silicon carbide active oxidation and sublimation was not observed directly on the attacked surface after test, but particle ejection suggests its presence during this test phase. Authors observed the strong dependence of ablation phenomenon upon static temperature and molar mass of oxidizing species at nozzle's throat and upon combustion time: an increase of these parameters increases the ablated surface. Two types of crack were observed: a first longitudinal one (type 1) is generated by jet separation and its consequent tangential thermal gradient; a circumferential one (type 2) depends on the stresses, generated during combustion or motor assembly. More tests would be necessary to better understand cracks initiation processes, propagation and their dependence on experimental conditions. Short metallic fibers addition avoids crack propagation in concrete, improving the durability of the nozzle at high temperature.

According to this study, SiC-based micro-concrete nozzle, with short metallic fibers addition, has a good thermo-mechanical resistance under a hybrid rocket motor environment. This material, therefore, could be a good candidate as a cheaper alternative to the classical nozzle materials, as graphite and refractory metals, to use in hybrid rocket motor. A necessary condition to its use might be the application of a specific surface treatment before the test, reducing surface porosities and improving its resistance to ablation, oxidation/sublimation and liquid phases generation. A possible approach could be the Chemical Vapor Deposition technique, to create a thin layer of less reactive material; another could be the use of a thin layer of thermoset ablative material, with a higher ablation heat, to delay ablation initiation.

\section{Acknowledgments}

Authors would like to thank CNES and Midi-Pyrenees region for the financial support to the Ph.D. thesis. Special thanks to PERSEUSPEGASE project leaders Jean Oswald and Christophe Magnière.

\section{References}

[1] Y. Maisonneuve, Ablation of solid-fuel booster nozzle materials, Aerosp. Sci. Technol. 4 (1997) 277-289.

[2] K.K. Kuo, K. Brezinsky, S. Hanagud, S. Irle, J.H. Koo, M.C. Lin, S. Menon, J. Morral, J. Musaev, J. Seitzman, A. Wilkinson, V. Yang, R.A. Yetter, Fundamental Understanding of Propellant/Nozzle Interaction for Rocket Nozzle Erosion Minimization Under Very High Pressure Conditions, US Office of Naval Research, Arlington, VA, 2005.

[3] R. Acharya, K.K. Kuo, Effect of pressure and propellant composition on graphite rocket nozzle erosion rate, J. Propuls. Power 23 (6) (2007) 1242-1254.

[4] D. Bianchi, Modeling of Ablation Phenomena in Space Applications (Ph.D. thesis), Università di Roma La Sapienza, 2007.

[5] D. Bianchi, F. Nasuti, Carbon-carbon nozzle erosion and shape change in fullscale solid-rocket motors, J. Propuls. Power 28 (4) (2012) 820-830.

[6] D. Bianchi, A. Turchi, F. Nasuti, M. Onofri, Chemical erosion of carbon-phenolic rocket nozzles with finite-rate surface chemistry, J. Propuls. Power 29 (5) (2013) 1220-1230.

[7] D. Bianchi, F. Nasuti, Numerical analysis of nozzle material thermochemical erosion in hybrid rocket engines, J. Propuls. Power 29 (3) (2013) 547-558.

[8] E.P. Pakhomov, A.I. Romanov, L.G. Smirnova, L.B. Borovkova, T.A. Melekhina, 
Testing linings of TsBG concrete in a high-temperature current of combustion products, Ogneupory 5 (1990) 253-256.

[9] S.V. Beshta, V B. Khabenskii, E.V. Krushinov, S.A. Vitol, T.Y. Pautova, E.

K. Kalyago, Y.B. Petrov, D.B. Lopukh, A.Y. Pechenkov, A.M. Lyubomirov, I.

$\mathrm{V}$. Kulagin, Interaction between a $\mathrm{UO}_{2}+{ }_{-}-\mathrm{ZrO}_{2}-\mathrm{Fe}(\mathrm{Cr}, \mathrm{Ni}) \mathrm{O}_{y}$ melt and a concrete based on $\mathrm{ZrO}_{2}$, Refract. Ind. Ceram. 41 (1) (2000) 19-23.

[10] Y. Maruyama, Y. Kojima, M. Tahara, H. Nagasaka, M. Kato, A.A. Kolodeshnikov, V.S. Zhdanov, Y.S. Vassiliev, A study on concrete degradation during molten core/concrete interactions, Nucl. Eng. Des. 236 (2006) 2237-2244.

[11] C. Journeau, J.M. Bonnet, E. Boccaccio, P. Piluso, J. Monerris, M. Breton, G. Fritz, T. Sevon, P.H. Pankakoski, S. Holmstrom, J. Virta, European experiment on 2-D molten core concrete interaction : hecla and vulcano, Nucl. Technol. 170 (2010) 189-200.

[12] J. Liang, N.I. Hossain, K. Schenker, Final Report on the Study of Flame Trench Concrete Material, Louisiana State University, Department of Mechanical Engineering, USA.

[13] R. D'Elia, G. Bernhart, T. Cutard, G. Peraudeau, M. Balat-Pichelin, Preliminary tests of silicon carbide based concretes for hybrid rocket nozzles in a solar furnace, Acta Astronaut. 99 (1) (2014) 242-251.

[14] P.C. Hewlett, Lea's Chemistry of Cement and Concrete, 4th Edition, 2001.

[15] W.E. Lee, W. Vieira, S. Zhang, G.K. Ahari, H. Sarpoolaky, C. Parr, Castable refractory concretes, Int. Mater. Rev. 46 (3) (2001) 145-167.

[16] E. Cailleux, T. Cutard, G. Bernhart, Study of a ceramic refractory reinforced with metallic fibres: from the microstructure to the mechanical behaviour, Ind. Ceram. 25 (1) (2005) 21-26.

[17] G.P. Sutton, O. Biblarz, Rocket Propulsion Elements, John Wiley \& Sons, New York 2001, pp. 69-71 7th Edition.
[18] T.V. Nguyen, J.L. Pieper, Nozzle separation prediction techniques and controlling techniques, AIAA Pap. (1996).

[19] G.P. Sutton, O. Biblarz, Rocket Propulsion Elements, John Wiley \& Sons, New York 2001, pp. 592-620 7th Edition.

[20] R.C. Bunker, A. Prince, Hybrid rocket motor nozzle material predictions and results, AIAA Pap. (1992) 92-3591.

[21] D. Bianchi, F. Nasuti, M. Onofri, E. Martelli, Thermochemical erosion analysis for graphite/carbon-carbon rocket nozzles, J. Propuls. Power 27 (1) (2011) 197-205.

[22] P. Thakre, V. Yang, Chemical erosion of carbon-carbon/graphite nozzles in solid-propellant rocket motors, J. Propuls. Power 24 (4) (2008) 822-833.

[23] G.A. Marxman, M. Gilbert, Turbulent boundary layer combustion in the hybrid rocket, in: Proceedings of the Ninth International Symposium on Combustion, The Combustion Institute, 1963, pp. 371-383.

[24] G.A. Marxman, Boundary layer combustion in propulsion, in: Proccedings of the Eleventh International Symposium on Combustion, The Combustion Institute, 1967, pp. 269-289.

[25] B. Cantwell, A. Karabeyoglu, D. Altman, Recent advances in hybrid propulsion, Int. J. Energ. Mater. Chem. Propuls. 9 (4) (2010) 305-326.

[26] E. Cailleux, T. Cutard, G. Bernhart, Pullout of metallic fibres from a ceramic refractory matrix, Compos. Part A: Appl. Sci. Manuf. 33 (10) (2002) 1461-1466.

[27] E. Cailleux, T. Cutard, G. Bernhart, Pullout of steel fibres from a refractory castable: experiment and modelling, Mech. Mater. 37 (4) (2005) 427-445.

[28] J.J. Orteu, T. Cutard, D. Garcia, E. Cailleux, L. Robert, Application of stereovision to the mechanical characterisation of ceramic refractories reinforced with metallic fibres, Strain (2007) 96-108. 